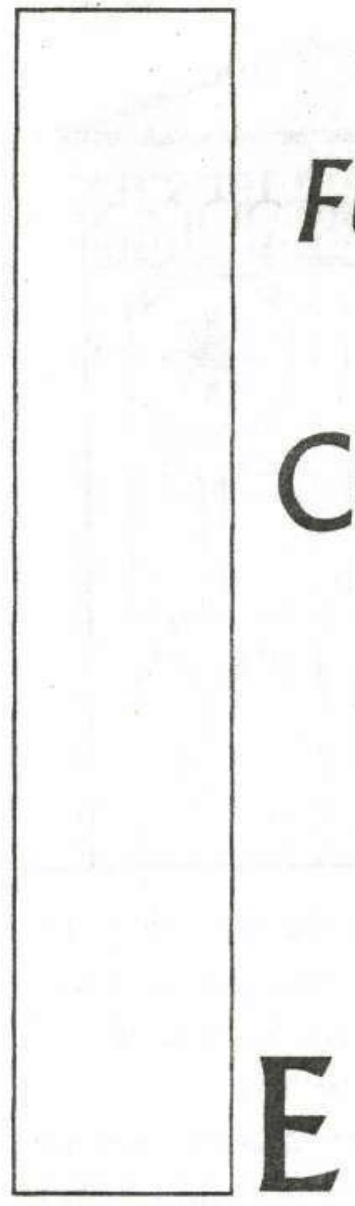

A n f o r a

1 constructivismo tiene ya varias décadas de desarrollo en el campo de distintos saberes, en diferentes partes del mundo. Son varios los enfoques que actualmente se da del constructivismo, habiendo posiciones irreconciliables.

En el campo pedagógico, son promisorios sus avances, y se fundamentan en la investigación. Los avances y desarrollo de los educandos son evidentes, lográndose personas con mejores capacidades humanas y sociales, creativas capaces de una comunicación mejor, con posibilidades de resolver problemas, abiertas, con sensibilidad en el campo de los valores.

La calidad de la educación se ha visto 
mejorada, y las distintas relaciones que se dan en el proceso pedagógico se han cualificado. De cara a la crisis por la que atraviesa la educación, el constructivismo se convierte en una posible alternativa; quizá sea una gota en un mar de problemas, pero necesitamos encontrar salidas dentro de plazos propuestos.

El ser humano se construye en procesos de desarrollo; el conocimiento es construido en la relación que establecen el grupo y el sujeto con la realidad y con los otros. La realidad misma se está haciendo. Hablar de constructivismo es plantearse la propiedad de los procesos.

Para conceptuar sobre la pedagogía, se requiere abordar mínimamente los siguientes conceptos: conocimiento, enseñanza, aprendizaje, educando, profesor, didáctica. A continuación analizaremos cada uno de estos conceptos.

La pedagogía constructivista fundamenta las relaciones e interacciones entre los sujetos en la acción educativa orientada a problematizar, conflictuar los conocimientos, realizar elaboraciones más acordes con la realidad y buscar la coherencia

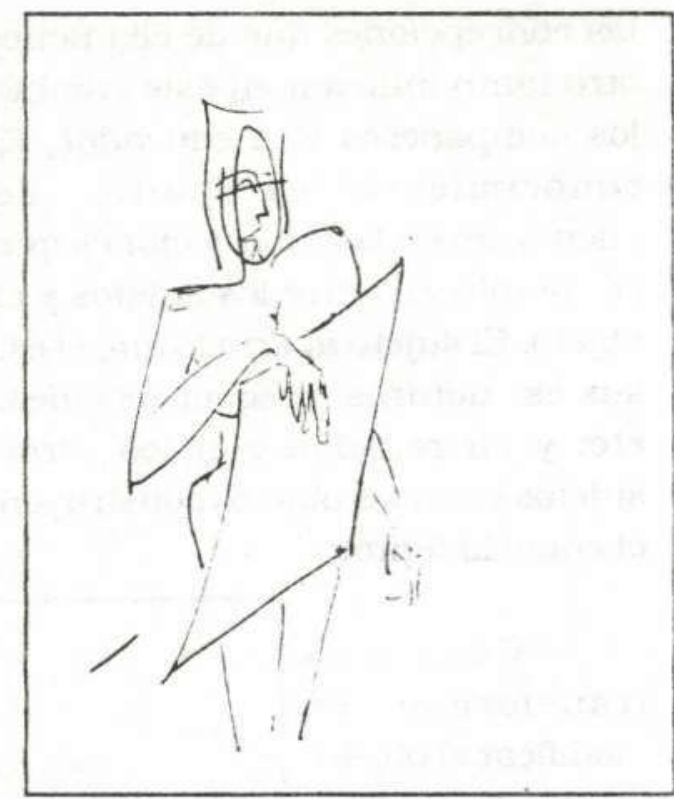

entre lo reflexionado, conceptuado. verbalizado y la acción de transformación de lo social y lo humano hacia mejores formas de convivencia.

\section{EL CONOCIMIENTO}

El conocimiento se da en la relación de los sujetos con el objeto.

El sujeto que conoce es activo. Posee intereses, se desarrolla, pasa de unos niveles de desarrollo a otros; se construye en las relaciones, es histórico, avanza en sus estructuras congnitivas. posee preconcepciones de la realidad.

La realidad influye en el sujeto, llevando a que éste cambie 
las concepciones que de ella tiene; otro tanto influyen en este cambio los compañeros y el educador. El conocimiento es punto de encuentro de las interacciones que se establecen entre los sujetos y el objeto. El sujeto aporta lo que él es, sus estructuras, preconcepciones. etc; y en relación con los otros sujetos y con los objetos construyen el conocimiento. la concepción que se tiene y la que los otros poseen y la realidad del objeto. El error es parte del conocimiento; el conocimiento se da por aproximaciones.

Los objetos de conocimiento poseen estructuras distintas, y los sujetos se acercan a ellos de manera diferente, es por eso que se plantean epistemes distintas.

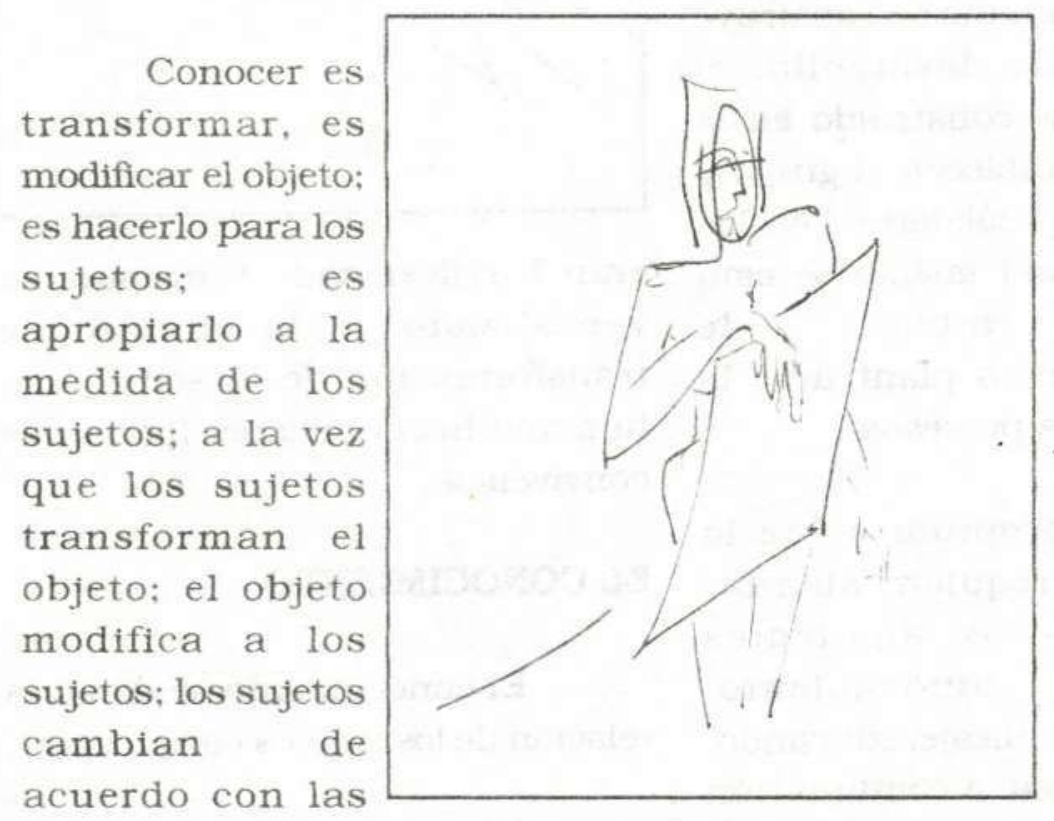

En el proceso de conocimiento de las matemáticas, el sujeto aporta: clasificación. seriación. jerarquización: es quien establece las relaciones, quien organiza.

En las ciencias naturales, el características del objeto, y de la sujeto construye a partir de los datos que recibe: medición, cuantificación; desde ahí replica. interacción

El sujeto asimila lo real transformándolo, acomoda y adapta a sus estructuras. El conocimiento es un proceso conflictivo; implica conflicto cognitivo, choque que se da entre

En las ciencias sociales se recibe y se aporta: datos, hechos, espacialidad, temporalidad, etc.

\section{EL APRENDIZAJE}

El aprendizaje es un proceso 
activo de los sujetos. Los sujetos aprenden poniendo en acción sus estructuras. El aprendizaje se da por medio del conflicto cognitivo, cuando entran en crisis los esquemas con los que el sujeto explicaba la realidad, y se pone en camino de encontrar una explicación más ajustada con la realidad del objeto y en la interacción con los otros sujetos. Implica que el sujeto se desestabiliza, pierde el equilibrio que había entre él y el medio. Entonces el sujeto se problematiza, se cuestiona, se da cuenta de la no correspondencia entre sus afirmaciones y la realidad que ahora se le presenta. El punto de partida de los nuevos aprendizajes son las preguntas, o interrogantes que se hace el sujeto. Al plantear problemas, buscan alternativas, $y$ se encuentran las soluciones más adecuadas. El aprendizaje 10 construye el sujeto, pero de manera cooperada, en las múltiples relaciones que establece, con el grupo de pares, con el educador, con la comunidad, con el mismo conocimiento, etc.

El aprendizaje parte de alguna necesidad o interés de la persona que participa en el proceso. Se aprende activamente; aprender haciendo. La acción debe preceder a la representación y guiarla; no se aprende nada si no es mediante conquista activa. Actividad que en el proceso educativo es entendida

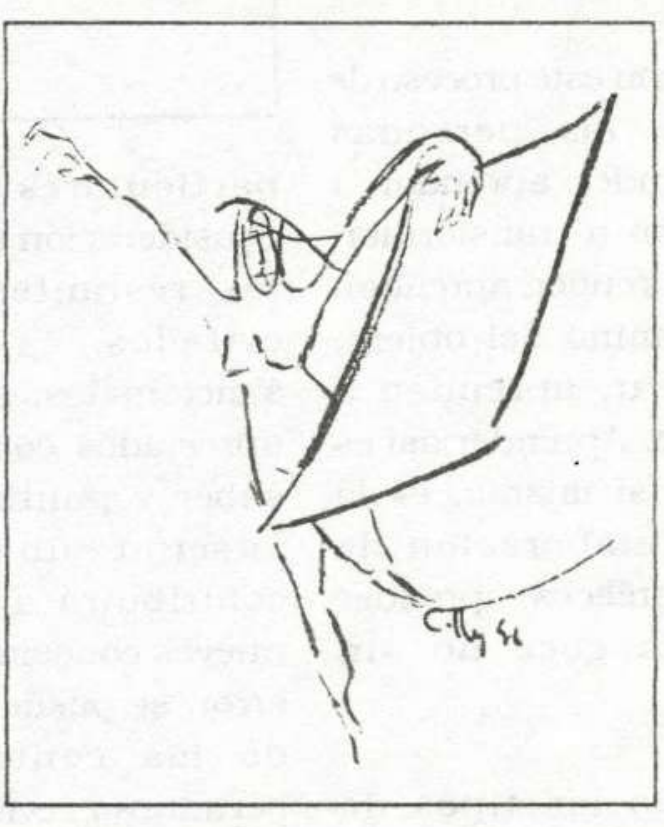
desde una doble vertiente: la acción como efecto sobre las cosas. es decir. c $0 \mathrm{~m}$ o experiencia fisica y la acción como colaboración social como esfuerzo de grupo, es decir c o $m$ o experiencia social. hipótesis acerca de los objetos y fenómenos con los que interactua. $\mathrm{El}$ proceso de aprendizaje implica momentos de conflicto entre las hipótesis propuestas por la persona, las hipótesis propuestas por los otros y las propiedades de los objetos, incluso entre las propias conceptualizaciones que ella ha elaborado. 
Los conflictos son superados por la persona progresivamente. con ayuda de los demás. alcanzando niveles de respuesta más complejos cada vez. Las personas grupal y personalmente elaboran su mundo a través de las acciones y reflexiones que realizan al interactuar con los otros, con los objetos, acontecimientos y procesos que conforman su realidad.

Se busca con este proceso de desarrollo que las personas aprendan a aprender, aprendan a conocer, aprendan a transformar, aprendan a desaprender, aprendan a recorrer el camino del objeto. aprendan a crear, aprendan a trabajar en grupo. Aprender así es estimulante por sí mismo, es la posibilidad de elaboración de aprendizajes autotélicos, aprender se convierte en goce no sin dificultad.

Son varios los tipos de aprendizaje: aprendizaje significativo, aprendizaje por repetición. aprendizaje por recepción, aprendizaje por descubrimiento guiado, aprendizaje por descubrimiento autónomo.

\section{EL ERROR}

Es el resultado de sucesivas centraciones en puntos de vista

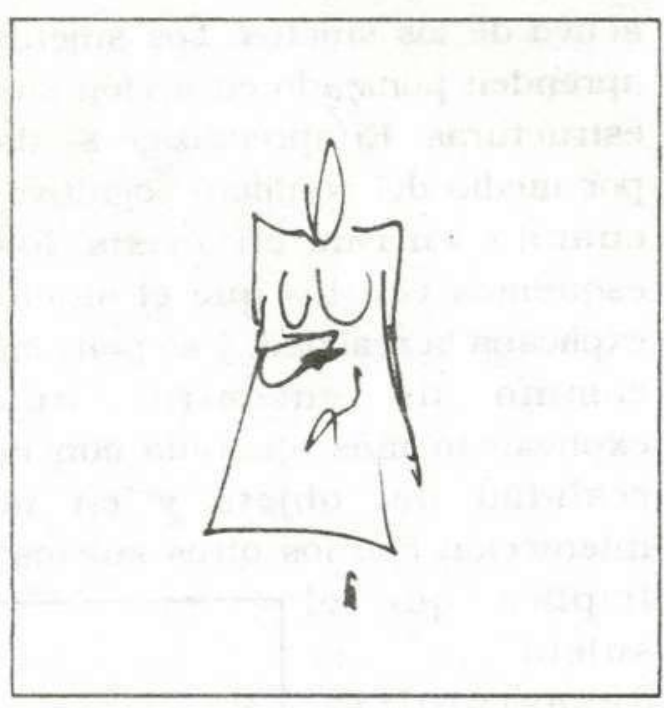

particulares que impiden la consideración simultánea de todos los restantes. No deben ser evitados, corregidos, ni sancionados, sino que deben ser apreciados comọ expresiones del saber y puntos de partida para suscitar una discusión que contribuirá a la adquisición de nuevos conocimientos. A partir del error, se pueden tomar conciencia de las contradicciones, que permitirán revisar las hipótesis.

\section{LA ENSEÑANZA}

Es un conjunto de mediaciones dadas por diferentes agentes orientados a estimular los actos de aprendizaje.

Es comunicación de doble vía en un continuo entre el educador y el educando, y otros 
agentes que intervienen en el proceso educativo. La enseñanza implica diálogo entre todos los que hacen parte del proceso educativo. es la posibilidad de negociación y renegociación cultural, es un diálogo abierto y permanente. siempre con la posibilidad de replanteamiento.

Enseñar es permitir aprender, es dejar que el otro aprenda, es no convertirse en obstáculo para el aprendizaje. Es facilitar le proceso de recorrido del objeto.

Enseñar implica ocupar diversas posiciones según los momentos del proceso formativo. unas veces es orientar, otras veces guiar, otras veces es canalizar el aprendizaje, otras veces es

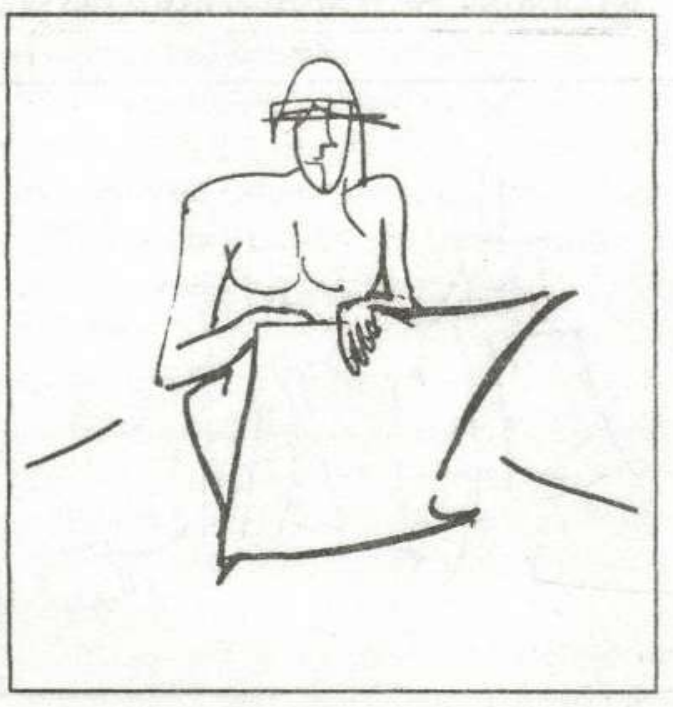

transmitir. informar, iniciar un proceso, seguir el proceso iniciado por los estudiantes, interactuar. acompañar. El proceso de enseñanza no puede pretender amoblar la mente.

En la enseñanza, todos nos enseñamos: los educandos a los educadores, los educadores a los educandos, los educandos entre si y las respectivas articulaciones con la comunidad y la sociedad.

Teniendo presente que existen epistemes distintas y relacionadas según los conocimientos, las enseñanzas también son diversas para hacer viable el proceso de construcción del conocimiento. La enseñanza está mediada por los saberes, los cuales se producen histórica y culturalmente.

\section{LA DIDACTICA}

La didáctica está en íntima relación con los conocimientos y el proceso de aprendizaje. En nuestra sociedad y cultura dependiente. se ha propugnado por una única didáctica, que desconoce tanto las estructuras particulares de la ciencia como las condiciones de pensamiento, vida y cultura de los distintos grupos sociales. La 
didáctica tradicional se ha reducido al uso de técnicas que faciliten el proceso de enseñanza.

La didáctica que proponemos hace énfasis en el juego y libre actividad del educando, los ambientes de libertad y responsabilidad social que sean acogedores físico, afectivo y humanamente, trabajos en grupos. acciones democráticas y cooperadas, que permitan la interacción entre compañeros y con el profesor (a), los métodos y motivos de competición se sustituyen por los de cooperación. consejo de clase, consejo escolar. trabajo a través de proyectos: trabajos en situaciones específicas. uso de equipos y materiales; no se trata de caer en simples manualidades o hacer cosas. Se pretende que los educandos se enfrenten realmente, no sólo por medio de su imaginación o poder verbal del profesor, a situaciones que rodean el aula y no son explotadas didácticamente.

A la práctica va unida la reflexión. La producción social es tanto intelectual como material. talleres que implican interacción teórico-práctica.

A través de la didáctica constructivista se provocan experiencias significativas. La investigación es el método de aprendizaje propuesto.

La cooperación. el intercambio intelectual, la confrontación de opiniones. provoca la descentración, induce a aceptar la relatividad de los propios puntos de visa. a situarse en perspectivas ajenas anteriormente ignoradas. Se realiza el esfuerzo por

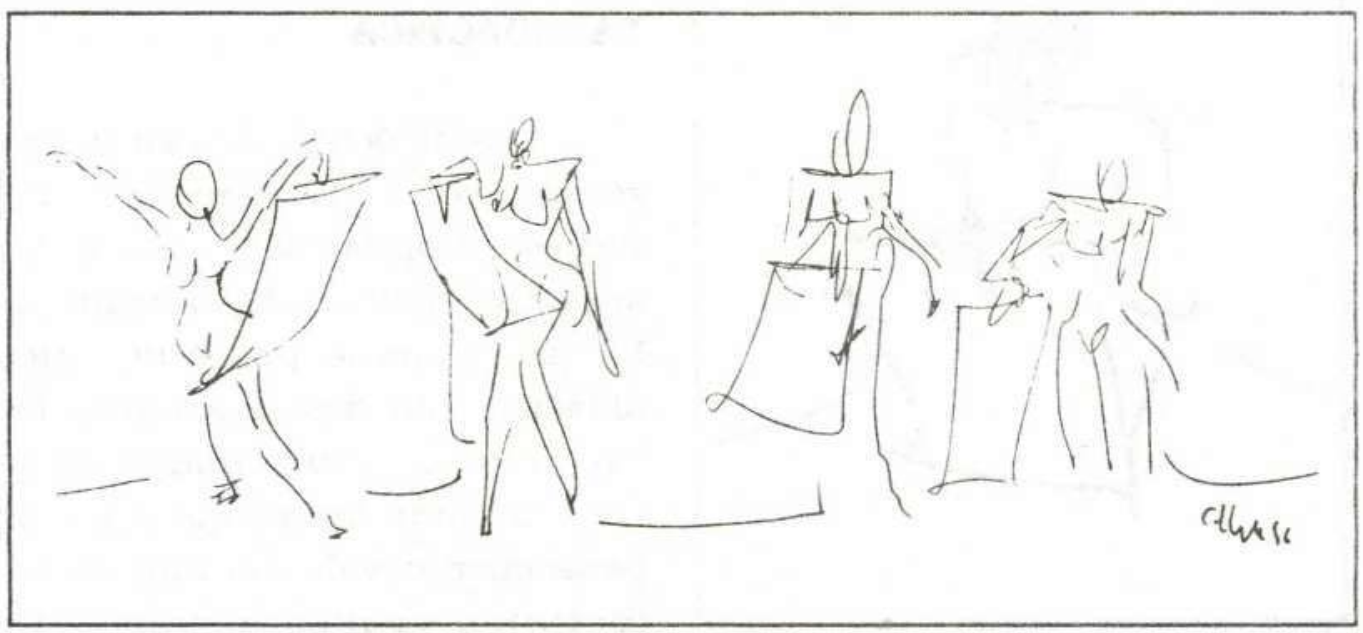




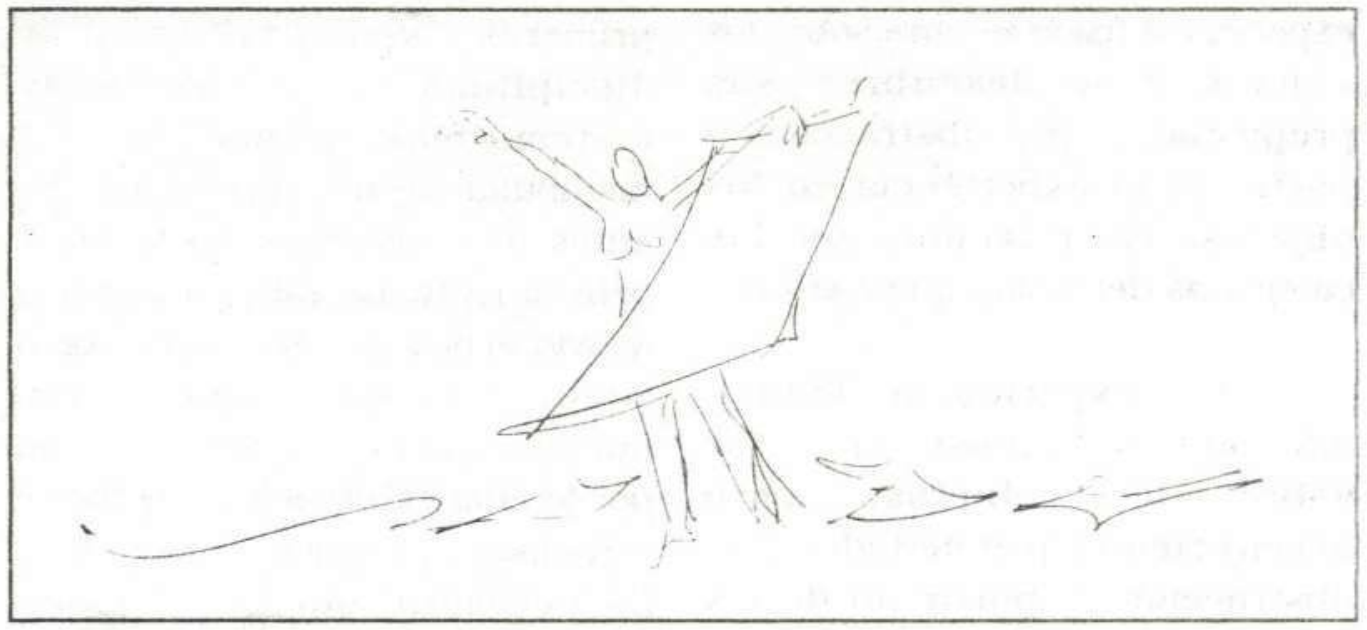

expresar pensamientos de forma coherente, comprensible y precisa. La operación intelectual, es a la vez condición y producto de la cooperación intelectual. El trabajo en equipo es provocación y control.

El educando no puede interpretar ningún hecho físico o social del entorno, sino es a través de un marco de relaciones. clasificaciones, comparaciones, órdenes y jerarquías. Es en el intercambio social $y$ en la experimentación física, donde el estudiante actúa, investiga, abstrae relaciones y coordina acciones.

El pensamiento del educando, sólo artificial y forzadamente puede sustraerse a consideraciones interdisciplinares: los problemas que enfrenta y las actividades que comprende, hacen referencia a campos amplios; se requiere de enfoque sistémico para abordar los problemas. La persona se ve abocada a operar mental y corporalmente en los problemas de la vida cotidiana.

Hay tres puntos importantes para la elección de métodos didácticos: la naturaleza de la inteligencia o del conocimiento. el papel de la experiencia en la formación de las nociones y el mecanismo de las transmisiones sociales o lingüísticas del educador al educando. No se trata de que el profesor haga experiencias ante el educando, sino que este debe hacerlas; de otra manera, se pierde el valor informativo y formático, que presenta la acción propia.

Al considerar por ejemplo dos tipos de experiencias: la experiencia física y la experiencia lógico-matemática. En la 
experiencia física se obra sobre los objetos y se descubren sus propiedades, por abstracción a partir de la experiencia en los objetos, en relación con las categorías del sujeto que conoce.

La experiencia lógicomatemática, consiste en obrar sobre los objetos, pero descubriendo propiedades por abstracción, a partir no de los objetos como tales, sino las acciones mismas que se ejercen sobre estos objetos; ejemplo alinear piedras, y descubrir que su número es el mismo, tanto si se procede de derecha a izquierda, como de izquierda a derecha (o en círculo, etc.); en este caso ni el orden, ni la suma numérica pertenece a las piedras, antes de que se les ordene

o cuente, y el descubrimiento de que la suma es independiente del o $r$ d $\mathrm{e}$ n (conmutatividad), ha consistido en abstraer estas constataciones de las acciones de enumerar ordenar.

El educando debe primero, sobre todo en las primeras etapas (incluso en las disciplinas

abstractas: matemáticas, geometría, etc: manipular objetos, superficies, etc.) antes de conocerlas mediante el pensamiento. La importancia de la actividad práctica disminuye con la edad, y lo que sigue siendo fundamental es la actividad mental. por lo cual es necesario romper el verbalismo en el proceso educativo. Es necesario que el educando organice laboratorios para que experimente: probetas, tubos. maderas, instrumentos de historia natural, etc.; desde el comienzo debe investigar, debe formarse una mente investigativa. Es necesario que aprendan a observar y a razonar observando individualmente y en común. 
los alumnos, e incluso acelerar su crecimiento mental, $\sin$ perjudicar su solidez.

U $n$ a es t r a t e g i a utilizada en las experiencias pedagógicas constructivistas es el consejo de clase, como lugar por excelencia de la palabra, lugar de encuentro, de diálogo. de auténtica comunicación entre todos. Se trata de consolidar verdaderos grupos, de generar camaradería, de establecer reglas de solidaridad y justicia. En las clases en las que utiliza la pedagogía constructivista, a través del consejo de clase, formado por los educandos y el profesor, ambos tienen voz y voto. Allí se elige el tema de trabajo, cómo se va a trabajar. los mecanismos, se organizan las normas de convivencia; para las decisiones se aportan argumentos. Elegir un tema puede llevar más de un día: durante este tiempo se busca documentación, se discute, se piensa, se realizan visitas. El tema elegido exige un compromiso muy serio, mientras dura su desarrollo: dias. semanas, meses. Los problemas de re 1 a c i o nes interpersonales. son trabajados con la misma seriedad

atención

que cualquier tema de trabajo.

El ambiente de aprendizaje. debe proveer. variedad de oportunidades de interacción con personas (educador, educando. grupos comunitarios). con instituciones (con las cuales se tiene alguinas relacion). con materiales (del medio. manipulables. impresos. tecnológicos, etc.), y consigo mismo (momento de reflexión autoevaluación).

Los materiales tienen que partir de la vida del educando para ser reconocidos por éste. y estar acordes con las distintas areas del conocimiento, con los fines que se pretenden y con los contenidos. Se hace necesario permanente revisión y ajuste de materiales, con base en recursos regionales, materiales que partan de contextos reales, lo que produce diversidad de estrategias 
didácticas en cada sitio.

\section{EL EDUCANDO}

El educando tiene interés en conocer. Es interactor. iniciador y seguidor. Interactua con los otros y con el mundo para comprender la realidad. Construye hipótesis e intenta verificarlas. Busca coherencia entre sus conceptualizaciones, revisa y ajusta sus teorías cuando descubre que éstas son insuficientes, para dar cuenta de la realidad. Organiza sus propias acciones y los objetos de la realidad a partir de una lógica propia.

El educando se sitúa como persona histórica, cultural y comunitaria; su desarrollo humano

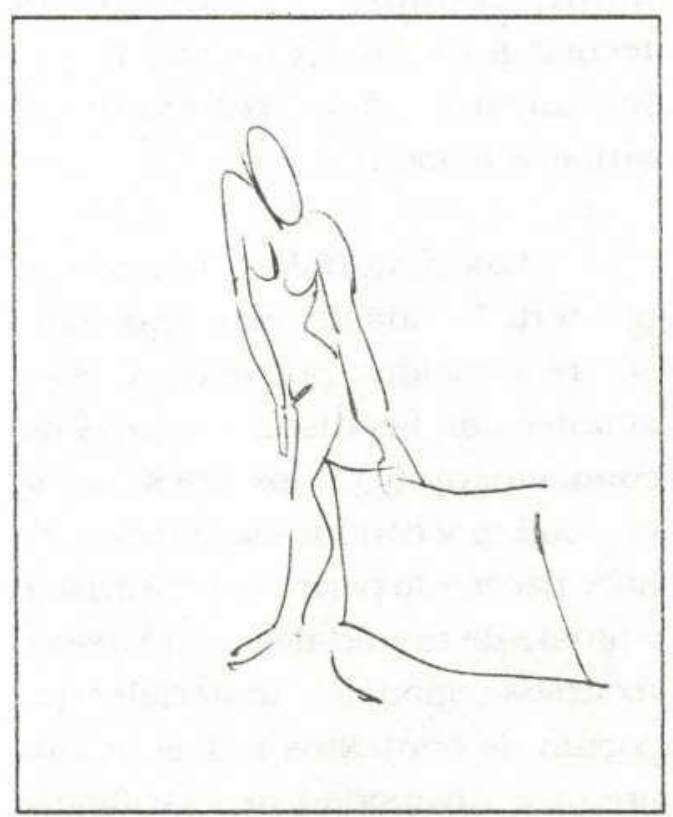

es integral e integrado en las esferas: comunicativa. socializante. afectiva, valoral, política, lúdica, sensible; capaz de optar por el bien común y de buscar la coherencia entre lo que piensa, hace y siente.

Educandos y profesores, en la propuesta pedagógica que venimos planteando, tienen varios papeles por cumplir: facilitadores del proceso de construcción, iniciadores, receptores, seguidores, interactores. observadores. orientadores. catalizadores, animadores. mayeutas, companeros en la apertura de caminos y posibilidades, auxiliares del libre y espontáneo desarrollo. creativos y artistas.

\section{EL PROFESOR}

Los problemas del desarrollo social y humano que enfrentamos hoy exigen por parte del educador la toma de conciencia del papel que le corresponde desempenar en los cambios educativos y en el proceso de llevar a la práctica una nueva propuesta pedagógica a partir de una concepción más humanista. social y desarrollo humano del educando y de su proceso de construcción, aproximación y apropiación del conocimiento.

El profesor debe tener en 
cuenta los siguientes principios:

a) Orientar el proceso de construcción en sus alumnos, posibilitando que éstos se apropien de las herramientas y técnicas, de sus conocimientos anteriores. experiencias individuales $y$ colectivas para encontrar nuevos caminos, resolver problemas. verificar hipótesis, confrontar resultados, clarificar sus conocimientos y ponerlos a prueba con las producciones científicas.

b) Crear ambientes pedagógicos y didácticos que propicien que los descubrimientos sean hechos por los educandos mediante la experimentación en grupo y personal.

c) Planificar y ejecutar diversas modalidades de trabajo $u$ organización que faciliten el proceso constructivo y favorezcan su autonomía.

d) Planificar de manera cooperada con los educandos el trabajo y la constatación de los progresos individuales y colectivos apoyándose en el nivel de desarrollo biológico, psicológico, social y cognitivo de los educandos.

e) Plantear su quehacer basándose en la integración equilibrada entre los resultados y objetivos que los educandos deben lograr y los procesos que debe motivar para que ellos construyan conocimientos válidos.

f) No sólo debe recurrir a técnicas pedagógicas para resolver problemas de aprendizaje. sino plantearse la problemática pedagógica.

didáctica. metodológica, involucrada en la situación educativa.

g) Desarrollar la capacidad para lograr el reconocimiento del saber y la experiencia de los otros (sus compañeros); para ver y sentir en ellos a nuevos interlocutores en la planificación de las actividades pedagógicas, en el descubrimiento

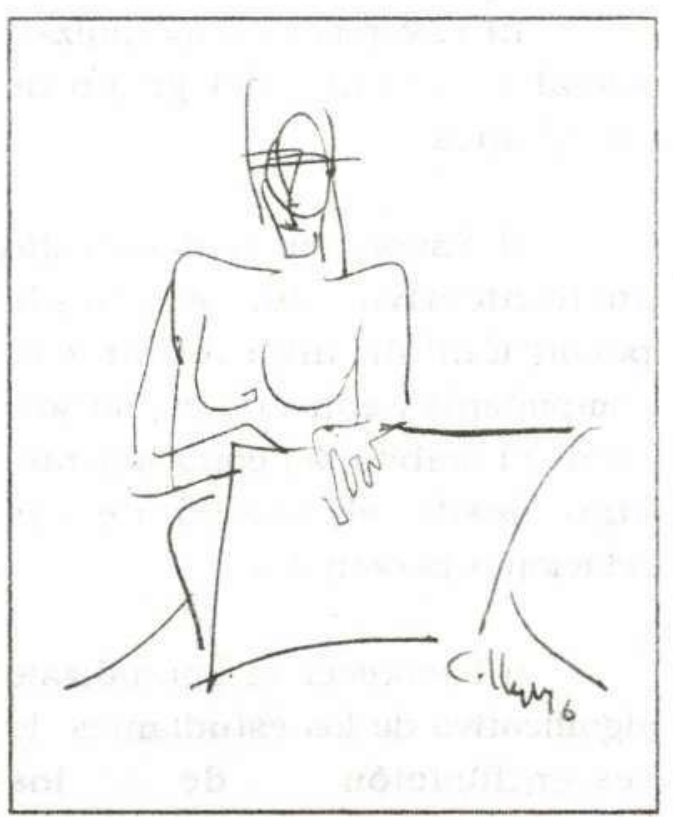




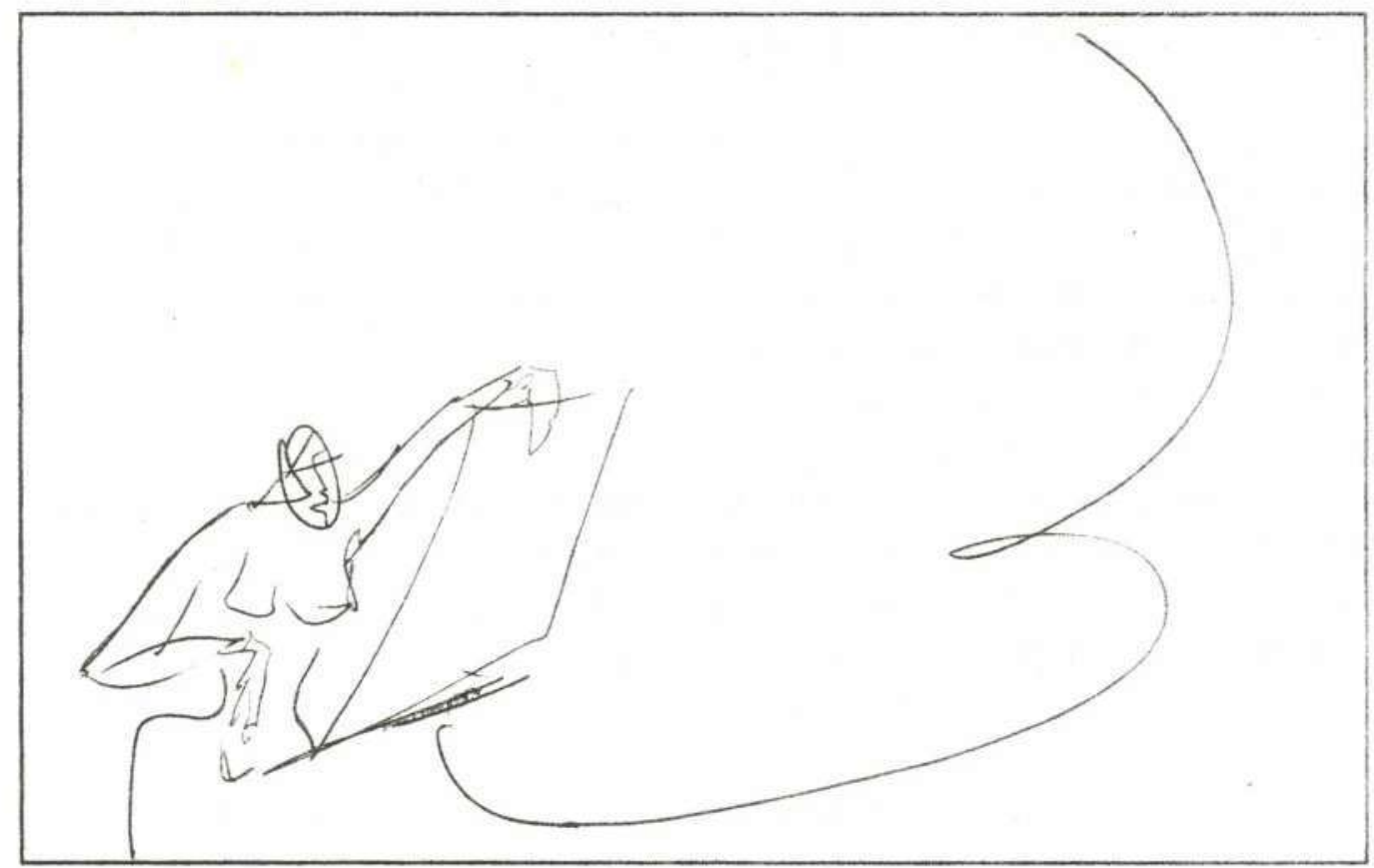

de las grandes posibilidades congnitivas de los educandos como en la valoración del interés que manifiestan por el aprendizaje.

h) Favorecer el aprendizaje social y colectivo del grupo de estudiantes.

i) Favorecer el desarrollo socio-afectivo del educando permitiéndole interactuar con compañeros y educadores, no sólo desde el ámbito del conocimiento, sino desde el campo de las relaciones personales.

j) Favorecer el aprendizaje significativo de los estudiantes, la resignificación de conocimientos, a partir de los conocimientos previos que poseen los educandos..

k) Ser orientador, animador. confrontador, comunicador, problematizador, acompañante. auspiciador de acuerdos. facilitador de la acción del educando y de la participación del grupo.

1) Ganar su autoridad en el saber y capacidad pedagógica, lo cual le permitirá establecer relaciones de cooperación con los educandos, las familias y la comunidad, facilitando la participación democrática de todos, estimulando la integración, la ccoperación, la solidaridad; 
permitiendo elevar a nuevos niveles de autoestima a los agentes educativos.

m) Coordinar sus acciones con otros profesores, con la dirección de los programas, y en la medida de lo posible, con las familias, la comunidad y la sociedad.

n) Contribuir a generar ambientes creativos de aprendizaje.

ñ) Contribuir a organizar las actividades, a asegurar los intercambios entre los estudiantes. Respetar las decisiones tomadas por éstos, no sin antes interpelar y contribuir a la búsqueda, alentando de manera sistemática la toma de decisiones. Acordar con los estudiantes los procesos y actividades que se van a llevar a cabo.

o) Fomentar el desarrollo propio de las diversas culturas.

p) Contribuir a generar currículos problemáticos.

q) Ser investigador $y$ constructor de su propio desarrollo humano. en actitud permanente de cambio.

r) fomentar relaciones en el quehacer pedagógico que conduzcan a gestar una ETICA CIUDADANA y a enriquecer los procesos del mundo, de la vida y de la cotidianidad.
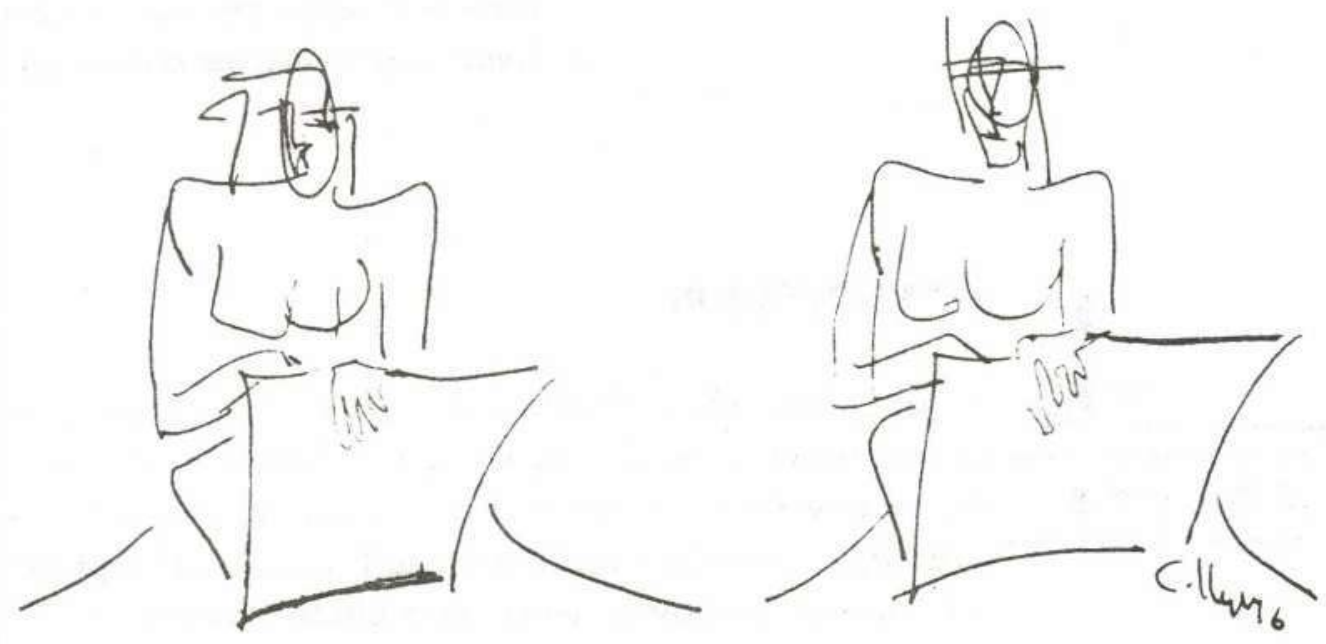